\title{
PANCASILA SEBAGAI SUMBER SEGALA SUMBER HUKUM DAN KEKERASAN ATAS NAMA AGAMA DI INDONESIA
}

\author{
Christina Maya Indah Susilowati \\ Fakultas Hukum Universitas Kristen Satya Wacana \\ Jalan Diponegoro No. 52-60 Salatiga \\ Email: mayauksw@yahoo.co.id
}

\begin{abstract}
Indonesia as a pluralism country face the challenges to build social relation in harmony. Identical Politic of multiculturalism had reduce cohesivity in national level which hadnt establehed until recent time. The lack of social cohesion in society divided as a sign of contitutional problematical. First, Does the reflection toward constitution adaptable for creating harmonization of society, and the second Does consttutional culture in society had built comprehensively? The diversity of indonesia society can co exsistence of life in the Pancasila, Constitution of Indonesia Number 1945 and amandemen, and regulation. The important point is how to make an contituion to be a life constitution as a the living constitution to society and the nation of Indonesia. Law should be able to fulfill social need which the role as a human security.
\end{abstract}

Keywords : Pancasila; Violence On The Behalf OfFaith.

\begin{abstract}
Abstrak
Indonesia sebagai negara majemuk agama menghadapi tantangan untuk membangun relasi sosial yang harmonis.Politik identitas keragaman mereduksi kohesivitas aras nasional yang belum mapan sampai saat ini.Buruknya kohesi sosial pada masyarakat terbelah menjadi tanda problema konstitusional.Pertama refleksi terhadap apakah konsitusional memadai penciptaan masyarakat toleran, dan kedua apakah kultur berkonstitusi masyarakat bisa dibangun secara utuh dan luas.Kemajemukan masyarakat Indonesia dapat hidup koeksisten dalam Pancasila, konstitusi UUD RI 1945 dan amandemennya serta perundang-undangan yang ada. Point pentingnya adalah bagaimana supaya konsitusi menjadi suatu konsitusi yang hidup (the living constitution) bagi kehidupan bermasyarakat dan bernegara di Indonesia.Hukum seyogyanya juga mampu memenuhi suatu kebutuhan sosial yang dimaksud dengan tetap berperan sebagai "Human security".
\end{abstract}

Kata kunci : Pancasila; Kekerasan Atas Nama Agama

\section{A. Pendahuluan}

Indonesia memiliki karakter sebagai masyarakat yang berideologi multikultural. Keragaman ideologi, suku, agama, strata social, ekonomi, dan politik merupakan suatu objek peripheral dalam pengelolaan perdamaian melalui revitalisasi Pancasila. Pada satu sisi keragaman Bangsa merupakan suatu kekayaan bangsa oleh karena memiliki panutan nilai moral, etis, dan spiritual . Pada sisi lain maka akan menjadi suatu celah potensi konflik, di mana bila tidak dikelola dengan baik akan memunculkan disharmonisasi, segregasi dan bahkan dehumanisasi. Pancasila yang berkarakter Bhinneka Tunggal Ika menjadi landasan pandangan hidup dan landasan sistem hukum nasionaldalam mengelola kehidupan pluralitas di Indonisia.

Bangsa Indonesia merupakan bangsa yang majemuk. khususnya dalam hal ini pluralitas agama. Dalam masyarakat yang multi kultur/plural, bisa saja terjadi di dalamnya terdapat hubungan antar kekuatan masyarakat dalam varian kemajemukan yang tidak simetris dan hadir dalam bentuk dominasi, hegemoni dan kontestasi. Konflik yang muncul dalam kehidupan keberagamaan muncul karena radikalisasi agama yang tidak memandang kesetaraan antar agama dalam interaksi sosialnya.

Dalam negara hukum Pancasila terdapat dua nilai mendasar, yaitu pertama, kebebasan beragama harus mengacu pada makna yang 
positif sehingga pengingkaran terhadap Tuhan Yang Maha Esa tidak dibenarkan; kedua, ada hubungan yang erat antara agama dan negara. Negara hukum Pancasila berpandangan bahwa manusia dilahirkan dalam hubungannya atau keberadaanya dengan Tuhan Yang Maha Esa. Para pendiri negara menyadari bahwa negara Indoneia tidak terbentuk karena perjanjian melainkan atas berkat rahmat Allah Yang Maha Kuasa dan dengan didorong oleh keinginan luhur, supaya berkehidupan kebangsaan yang bebas.

Prinsip Ketuhanan Yang Maha Esa merupakan prinsip pertama dari dasar negara Indonesia. Soekarno pada 1 Juni 1945, ketika berbicara mengenai dasar negara menyatakan:

"Prinsip Ketuhanan! Bukan saja bangsa Indonesia ber-Tuhan, tetapi masingmasing orang Indonesia hendaknya berTuhan. Tuhannya sendiri. Yang Kristen menyembah Tuhan menurut petunjuk Isa Al Masih, yang Islam menurut petunjuk Nabi Muhammad SAW orang Budha menjalankan ibadatnya menurut kitab-kitab yang ada padanya. Tetapi marilah kita semuanya ber-Tuhan. Hendaknya negara Indonesia ialah negara yang tiap-tiap orangnya dapat menyembah Tuhannya dengan leluasa. Segenap rakyat hendaknya ber-Tuhan. Secara kebudayaan yakni dengan tiada "egoisme agama". Dan hendaknya Negara Indonesia satu negara yang berTuhan".

Dalam konstelasi demikian, Pancasila yang dimiliki bangsa Indonesia sebagai sumber segala sumber hukum dan kekerasan atas nama agama di Indonesia memberi solusi untuk merekonstruksi kembali wawasan kebangsaan dan merekonsiliasi friksi-friksi antar keberagamanan. Pertanyaan yang ada adalah bagaimana Pancasila bisa menjadi alat pemersatu dan alat perekat kohesi social dalam masyarakat Indonesia yang beragam?

\section{B. Pembahasan}

1. Pancasila sebagai "The Peculiar From Social Life".

Pancasila merupakan sumber segala sumber hukum negara.2Penempatan Pancasila sebagai sumber segala sumber hukum negara sesuai dengan Pembukaan UUD 1945 alinea keempat, yait KeTuhanan Yang Maha Esa, Kemanusiaan yang adil dan beradab, Persatuan Indonesia, Kerakyatan yang dipimpin oleh Hikmat Kebijaksanaan Dalam Permusayawaratan Perwakilan, dan Keadilan Sosial bagi seluruh Rakyat Indonesia. Para pendiri negara telah memilih suatu paradigma bernegara yang tidak hanya mengacu pada tradisi hukum Barat, melainkan juga berakar pada tradisi asli bangsa Indonesia. Paradigma bernegara itu dirumuskan dengan memadukan secara paripurna 5 (lima) prinsip bernegara, yakni Ketuhanan (theisme), kemanusiaan (humanisme), kebangsaan (nasionalisme), kerakyatan (demokrasi), dan keadilan sosial (sosialisme) ke dalam suatu konsep Pancasila. Kelima prinsip Pancasila itu mengandung nilai universal, tetapi juga memiliki basis partikularitas pada tradisi bangsa Indonesia. Dimensi universalitas dan partikularitas itu menyebabkan adanya ketegangan konseptual dalam Pancasila yang menunjukkan bahwa para pendiri negara Indonesia hendak mendirikan negara-bangsa berciri modern, tetapi tetap berbasis pada tradisi bangsa Indonesia. $^{3}$

Pancasila dikatakan sebagai sumber dari segala sumber hukum. Pancasila yang lahir dari dalam masyarakat, tentu merupakan suatu landasan nilai yang hidup dalam masyarakat. Pancasila bukanlah suatu tertib norma hukum yang berisi nilai atau perintah yang ditentukan oleh penguasa (law is a command of authority). Sebagai dokumen social anthropology bangsa Indonesia, dimana Pancasila adalah hukum yang hidup dalam masyarakat Indonesia yang tumbuh dan berkembang dalam masyarakat

1. Ali Taher Parasong, "Internalisasi Nilai-Nilai Pancasila Dalam Pembentukan Perundang-undangan", tersedia di website https://fh.umj.ac.id, diakses pada tanggal 29 Februari 2016.

2. Teguh Prasetyo, 2016, Sistem Hukum Pancasila (Sistem, Sistem Hukum dan Pembentukan Peraturan Perundangundangan di Indoensia, Perspektif Teori Keadilan Bermartabat, Bandung, Nusa Media, hlm.43.

3. Aidul Fitriciada, "Negara Hukum Indonesia : Dekolonisasi dan Rekonstruksi Tradisi", Jurnal Hukum Ius Quia Iustum, Vol. 19, No.4, Oktober 2012, ISSN 0854-8498, hlm. 491 
Indoensia, maka sudah seharusnya sebenarnya Pancasila memiliki daya laku yang efektif.

Pancasila bukanlah hal terberi melainkan tumbuh dari dalam masyarakat Indonesia. Presiden Sukarno hanyalah penggali saja the living law yang kemudian dikonsensuskan secara politik sebagai dasar negara. Pancasila adalah pengukuhan dari pola kebiasaan dan tingkah laku yang berada dari dalam masyarakat. Pancasila sebagai landasan yang menjiwai tertib hukum dan menjadi dasar negara bukanlah sesuatu yang diciptakan oleh pemrintah, melainkan ditemukan dalam masyarakat . Pancasila dengan Bhinneka Tunggal Ikanya dirumuskan oleh Founding father bangsa Indonesia, memang diangkat dari karya besar Mpu Prapanca dalam buku Sutasoma, menunjukkan nilai-nilai luhur yang menjadi dasar mengatur kehidupan berbangsa dan bernegara Indonesia (a peculiar form of social life bangsa Indonesia).

\section{Pancasila, Hukum dan Radikalisasi Agama}

Dalam menghadapi persoalan radikalisasi agama dan kekerasan maka cita $\mathrm{h} \mathrm{u} \mathrm{k} \mathrm{u} \mathrm{m} \mathrm{y} \mathrm{a} \mathrm{n} \mathrm{g} \mathrm{b} \mathrm{e} \mathrm{r} \mathrm{m} \mathrm{a} \mathrm{k} \mathrm{n} \mathrm{a}$ perlindungan,kebenaran dan keadilan menjadi harapan untuk mampu menjawab. Pendekatan hukum yang semata-mata dengan pendekatan perundang-undangan bukanlah satu-satunya jalan menuju suatu ketertiban dan dalam kerangka masyarakat damai sejahtera. Hukum hanyalah salah sarana dalam menciptakan sosial defence dan sosial welfare. Dalam kerangka kebijakan hukum, maka sarana penal (hukum pidana) merupakan suatu penyelesaian yang simptomatis saja dan bukan mengarah pada akar kausatif.

Salah satu upaya kebijakan hukum berupa sarana non penal adalah berupa kebijakan non punishment yang bersifat persuasive, preventive, mengakomodasi medical treatment model. Bentuk eliminasi deradikalisasi agama antara lain dengan menjalankan perspektif pluralism yang menitikberatkan pada dialog antar umat beragama. Tujuan dialog ini dikemukakan oleh Knitter, adalah :

The purpose of dialogue is not only a clarifying exchange of information about each other, but that all participants have the opportunity to bring their "own "truth claims" to the conversation so that their religious self understanding can be "different, deepened, and even transformed for having learned some thing from the other.

Pluralisme agama adalah persoalan bagamana kehidupan antar umat Beragama saling menerima perbedaaan, menghilangkan pra sangka, dan kebencian. Oleh karenanya penanganan radikalisme serta perilaku kekerasan dalam beragama tidak bisa hanya ditanggapi secara reaktif, partial dan represifitas hokum belaka. Upaya komprehensif dan berkelanjutan melalui pendidikan perdamaian dalam strategi pendidikan kebangsaan Indonesia. Dalam era otonomi daerah, keterbukaan dan liberalisasi serta perkembangan globalisasi dan teknologi informasi, maka beragam pertentangan ideology dan kekerasan ideology politis yang dikaitkan dengan aliran keagamaan dengan mudah akan mempengaruhi masyarakat.Hal ini akan menjadi ancaman serius apabila konflik berbau keagamaan terkait langsung dengan kekuatan ideology politik keagamaan yang sejatinya berujung pada perebutan kekuasaan.

Radikalisme memiliki istilah yang banyak varian, namun dalam benang merahnya pada terminologi radikalisme agama, hal ini diidentikkan dengan kelompok keagamaan yang memperjuangkan prinsip keagamaan secara mendasar dengan cara $\mathrm{ke} \mathrm{tat,} \mathrm{keras}, \mathrm{te} \mathrm{g}$ a $\mathrm{tan} \mathrm{pa}$ kompromi.Pengertian ini sepintas berkonotasi kekerasan fisik, padahal radikalisme merupakan pertentangan yang sifatnya ideologis. Atas dasar itu menurut kamus besar bahasa Indonesia, radikalisme merupakan paham (isme), tindakan yang melekat pada seseorang atau kelompok yang menginginkan perubahan baik sosial, politik

4.Paul F. Knitter, 2005, "is the Pluralist model a Western Imposition?: A Response in five voices. "In The Myth of Religious Superiority: A Multifaith Exploration, edited by Paul F.Knitter, New York, Orbics Books, p.33. 
dengan menggunakan kekerasan, berpikir asasi, dan bertindak ekstrem. ${ }^{5}$

Jumlah intoleransi berlatar belakang perbedaan keyakinan agama di Indonesia yang dilaporkan ke Komisi Nasional Hak Asasi Manusia tahun 2015 mencapai 95 kasus, yang terdiri dari antara lain: kasus pelarangan pendirian rumah ibadah, kasus penghalangan berlangsungnya kegiatan keagamaan, serta kasus diskriminasi berdasar keyakinan agama. Hal mana jumlah ini meningkat dari 74 kasus pada 2014. Hasil pemetaan temuan Badan Nasional Penanggulangan teorisme di 32 Propinsi menunjukkan bahwa pemahaman keagamaan masyarakat berada pada tingkat "waspada" terhadap radikalisme yaitu sebesar $66,3 \%$. Kebencian dan kemarahan lebih mengemuka menutupi wajah agama yang sebenarnya sejuk dan cinta damai.

Dalam UUD NRI 1945 beserta amandemennya telah tegas tercantum adanya pengakuan dan jaminan tentang hak asasi manusia, agama, dan kebudayaan. UUD RI 1945 telah melampaui nilai particular atau dominan tertentu sehingga konstitusi Indonesia sudah mereleksi dan merepresentasikan pluralitas bangsa Indonesia. Di samping itu, telah diratifikasi konvensi internasional hak sipil, politik, ekonomi, sosial, budaya dengan UU No. 11 Tahun 2005. Diakui Hak sipil dan kebebasan : hak atas identitas da perindungannya, berekspresi mengeluarkan pendapat, berpikir, berhati nurani dan beragama, berorganisasi dan berkumpul secara damai, perlindungan atas kehidupan pribadi, akses informasi yang layak, bebas dari kekerasan. Sudah diratifikasi pula konvensi internasional tentang penghapusan segala bentuk diskriminasi rasial 1965 dengan UU No. 29 Tahun 1999, dan UU No. 39 Tahun 1999 tentang Hak Asasi Manusia .

Berdasarkan instrument hukum yang ada, maka nampak bahwa kemajemukan masyarakat Indonesiadapat hidup koeksisten dalam naungan konstitusi UUD NKRI 1945 dan amandemennya serta perundangundangan yang ada. Persoalan yang urgent adalah bagaimana supaya konsitusi dan regulasi tersebut di atas menjadi suatu konsitusi yang hidup (the living constitution) bagi kehidupan bermasyarakat dan bernegara di Indonesia.'Fakta yang ada sekarang adalah adanya disharmonisasi dan intoleransi beragama yang menyulut konflik dan disertai kekerasan horizontal dan kekerasan structural. Bukan hanya masyarakat yang menjadi pelaku pelanggaran hak konstitusional, namun aparatur negara juga menjadi pelaku kekerasan atas nama justifikasi agama dan moral.Proses-proses ekslusif yang elitis dalam penyusunan kebijakan hukum dan implementasinya menandakan adanya isu intoleransi beragama yang mengemuka.

Menurut Beck Fords, ${ }^{8}$ penerimaan lacceptability kehidupan religiositas memiliki beberapa dimensi, antara lain :

First, it can be about the scale of formal recognition of religious diversity by the state, asserting that each religion should be respected and protected by legal and constitutional guarantess. Emancipatory pluralism granted equal rights and facilitaties by the state. Identity based pluralism refers to individual or collective rights to religious freedom. Second, it can be sosial acceptance. Religious pluralism also refers the willingness of recognized religious groups to accept others as worthy partners or competitors in the public sphere. Third, religious pluralism refers to the positive evaluation among citizens that religious diversity and harmonious coexistence in their society are both desirable and achievable.

Berdasarkan terminology tersebut, religious pluralism dapat dianalisis dari pelbagai multi sosial dimensi, yakni perspektif kebebasan beragama dari negara, relasi antar agama, penerimaan "religiositas

\footnotetext{
5. Deputi Bidang Pencegahan, Perlindungan dan Deradikalisasi, 2015, Anak Muda Cerdas Mencegah Terorism, Badan

Nasional Penanggulangan Terorisme, hlm 29-31.

6. Ibid, hlm. 33

7. Munafrizal Manan, “Konstitusi Masyarakat terbelah”, Harian Kompas, 20 Agustus 2015, hlm 7.

8. James A. Becford, 2003, Sosial Theory and Religion, New York, Cambridge University Press, p. 56
} 
minority" sebagai anggota masyarakat yang terlegitimasi. Apabila dikaji dari Perspektif "rule of law" dalam socio legal perspective, maka persoalan religious pluralism bukan seutuhnya berada pada tataran consensus yang bersifat theology, tetapi juga lebih pada justifikasi atau legitimasi dari negara yang menterjemahkan nilai demokrasi, nilai human dignity, penafsiran monopoli negara atas kebenaran suatu ajaran. Pada tataran lain, "democratic religious pluralism" tidak hanya diperoleh karena kebijakan hukum oleh pemerintah, tetapi juga dipengaruhi oleh group-group sosial, institusi agama, dan penerimannya oleh semua anggota masyarakat.

Dalam persoalan pelayanan publik, maka hukum yang direpresentasikan oleh pejabat pelayan public juga acap dirasa menterjemahkan radikalisasi dimensi agama dalam tindakannya. Secara teoretik, menurut B.Libois dalam Haryatmoko: ${ }^{9}$ prinsip pelayanan publik ada tiga yakni kontinuitas, kontinuitas, kesetaraan, dan adaptif. Pada aspek kesetaraan, maka tidak ada diskriminasi dalam mendefinisikan kategori public. Tantangan dalam pelayanan public di Indonesia yang plural adalah kecenderungan disriminatif.Hal ini terait pula dengan netralitas layanan public, yakni tuntutan kepada lembaga layanan publik yang merupakan bentuk implementasi kebijakan hukum untuk bisa memenuhi layanan publik tanpa diskriminatif. Netralitas politik menjadi jaminan kontinuitas layanan publik sehingga pelayanan publik tidak mengutamakan kelompok masyarakat tertentu atau diskriminatif terhadap yang lain. ${ }^{10}$

Sikap diskriminatif berbasis SARA seringkali dipertunjukkan sebagai suatu kekerasan structural dalam bentuk PeraturanPeraturan Daerah yang mengatasnamakan agama dan moral untuk menjustifikasi pihak lain, maupun dalam keputusan-keputusan pejabat hukum lainnya seperti dalam perijinan rumah ibadah.Integritas lembaga layanan public menjadi absurd manakala memiliki kepentingan latent untuk melakukan diskriminasi layanan public berbasis SARA dengan melakukan favoritism dan tidak berusaha independen dan mengakomodasi HAM.Peraturan-Peraturan daerah yang diskriminatif ini tidak didasarkan pada analisis kebutuhan objektif, melainkan semata pada persoalan elektabilitas politik yang mengorbankan pluralitas bangsa, dan tidak mendidik manusia untuk menjadi toleran terhadap manusia lainnya. Inipun juga menjadi bentuk atau derivasi perilaku beragama yang kebetulan dilakukan oleh manusia-manusia yang memiliki akses kepada pembuatan hukum dan penegakan hukum. Radikalisme agama dalam suatu kekerasan structural menggunakan justifikasi hukum inilah yang juga menjadi keprihatinan bagi bangsa Indonesia yang pluralis.

Tuntutan terhadap hukum yang bersinergi dengan ideologi pluralisme Bangsa Indonesia, adalah wajah hukum yang nampak dalam kebijakan hukum sebagai suatu wajah integritas public yang berhabitus moral dan memiliki politik inklusif. Oleh karenanya sudah selayaknya hukum menjamin kehidupan keberagamaan yang kondusif dengan toleransi, dan menjamin penerimaan pluralitas agama dan menciptakan perlakuan hukum yang adil melawan semua bentuk diskriminatif. Pejabat hukum atau pejabatpublik secara luas bukanlah wakil kelompok agama tertentu, namun harus memperjuangkan toleransi dan budaya politik bersama. Oleh karenanya, wajah hukum penting untuk memaknai bahwa hukum ditujukan untuk membangun solidaritas sosial guna kesejahteraan sosial dan bukannya menjadi suatu alat kepentingan yang sectarian dan menolak pluralism.

\section{Politik Hukum Responsif Hak Asasi Manusia}

Politik hukum HAM responsive sebagai politik hukum yang berpihak pada semangat memberikan keadilan kepada kelompok marginal (Bringing justice to the people), dimulai dengan menempatkan politik hukum yang egaliter yang menempatkan ide kebangsaan sebagai pioritas utama, dengan menumbuhkan legal literacy yang

\footnotetext{
9. Haryatmoko, 2011, Etika Publik: Untuk Integritas Pejabat Publik dan Politisi, Jakarta, Gramedia Pustaka Utama, hlm 16-17.

10. Ibid, hlm 18 .
} 
membangun kesadaran hukum masyarakat dan pengampu kepentingan akan kehidupan harmonis beragama di Indonesia.

Pada tataran struktural, maka munculnya radikalisme agama dapat dikemukakan sebagai berikut :

a. Pengabaian akan kebutuhan untuk diakui.

Dikotomi antara mayoritas dan minoritas memunculkan kurangnya ruang untuk adanya pembauran antara mayoritas dan minoritas. Mayoritas merasa memiliki suatu posisi dominan yang tidak sama dengan minoritas dan menjadi superior yang mensubordiasi minoritas.

b. Dominasi dan hegemoni yang mengabaikan diversitas.

Dalam kerangka ini, maka seringkali dirujuk suatu budaya feodal seperti paternalistik, hierarkial, nepotisme yang mencederai demokrasi Pancasila. Maka perlu dieliminir dengan menentang budaya feodalisitk menjadi budaya yang egaliter yang menunjukkan kesamaderajatan. Dalam hal ini berarti muncul pemaksaan politik monokulturalisme .Dalam konstelasi praktek politik di Indonesai, isu SARA justru menjadi isu yang digaungkan dalam meraih elektabilitas suara dalam suatu pemilihian wakil politik. Kuatnya kekuasaan kelompok dominan yang cenderung mengontrol masyarakat mengarah pada pra sangka akan adanya "political society".

c. Kebijakan diskriminatif atau unfairness baik dalam law making dan law implementation. Adanya kemungkinan dominasi negara oleh kelompok kepentingan tertentu yang sectarian dan memiliki kekuasaan untuk mengakses kekuasaan dan informasi dan meminggirkan kelompok lainnya.

Di Indonesia setelah Suharto jatuh pada Tahun 1998, partisipasi politik menunjukan gejala kenaikkan yang sangat significant karena ketakutan pada masa orba dan memperoleh saluran pada masa orde reformasi.Bersamaan dengan itu, kerusuhan berlatar belakang SARA juga muncul seperti di Kalimantan, Maluku, Poso, Jawa. Maka, untuk menyikapi hal ini, mau tidak mau dalam konteks KeIndonesiaan, maka segenap lembaga sipil seperti lembaga pers, lembaga keagamaan, lembaga negara, civil society, dan segenap angota masyarakat memegang peran penting. Apalagi sejarah bangsa Indonesia mengajarkan tentang lahirnya Pancasila yang bertolak dari nilai luhur yang diakui bangsa.

Achmad Gunaryo mengemukakan bahwa dalam kehidupan agama terdapat symbol-simbol yang harus dihargai dan memiliki makna tersendiri. Ketika ada orang yang bergerak atas nama absolutely freedom, maka akan menimbulkan percikan konflik.dalam demokrasi, tidak membawa kebebasan mutlak. ${ }^{11}$ Melalui pendidikan politik dan pendidikan multikulturalistas, maka kemantapan bangsa Indonesia untuk berdemokratisasi yang menjunjung nilai toleransi akan memiminimalisir radikalisasi agama. Dengan demikian, hukumpun juga seharusnya menjunjung tinggi demokratisasi yang berkualitas dan menolak dipakainya agama sebagai alat memobilisasi SARA dan menolak legitimasi kekerasan atas nama demokrasi.

Diamond mengemukakan salah satu agenda untuk konsolidasi demokrasi perlu dibangun suatu rule of law yang sesungguhnya, dan membangun konsolidasi kekuatan masyarakat sipil dan media yang independen yang dapat memelihara modal sosial, partisipasi warga, membatasi tetapi memperkuat kewenangan konstitusional negara. ${ }^{12}$ Dalam kerangka Pluralisme, maka absolutisme klaim dalam agama dan ideology tidaklah tepat untuk masyarakat Indonesia yang plural. Untuk itu diperlukan suatu modal sosial untuk mengelola kehidupan masyarakat yangmajemuk, dalam perspektif pengelolaan konflik khususnya pada aspek

11. Achmad Gunaryo, 2013, dalam seminar Internasional Membangun Budaaya Perdamaian Melalui Pendidikan Perdamaian di Indonesia, SPWC kerja sama dengan UBCHEA dan Bina Dhrma, 29-30 Mei 2013, Prociding ISSN : 978-979-8154-82-9, hlm 49.

12. Larry Diamond, 2000, The End of The Third Wave and The start of The Fourth dalam Plattner, Marc F, Joao Carlos Espada, The Democratic Invention, Baltimore, The John Hopkins University Press, p.24. 
preventif. Dimaksudkan dengan modal sosial secara sederhana adalah jaringan sosial antara satu orang dengan orang lain (Halpern, 2005, 1). Sebagaimana dikatakan Putnam bahwa modal sosial adalah sebagai suatu ciri kehidupan sosial, jaringan, norma, dan kepercayaan yang memungkinkan orangorang bertindak bersama untuk mencapai tujuan bersama. Penguatan modal sosial melalui diseminasi nilai toleransi akan membuka suatu demokrasi deliberasi dalam memandang kehdupan eragama di Indonesia.

Dalam realitasnya, maka kehidupan keberagamaan di Indonesia tercoreng dengan radikalisasi agama atau kekerasan yang mengatasnamakan agama. Konflik menjadi t e r c i p t a d a $n$ p e r a m a i a $n$ dipertaruhkan.Kerentanan sosial yang mengganggu ketahanan sosial menjadi tercederai.Modal sosial bangsa Indonesia untuk hidup dalam suasana Bhinneka Tunggal Ika menjdi suatu hal yang perlu diperhatikan. Dalam konteks ini, maka hukum seyogyanya juga mampu memenuhi suatu kebutuhan sosial yang dimaksud dengan tetap berperan sebagai "Human security" .Konsep ini berbeda dengan konsep keamanan negara (state security). Tetapi human security adalah lebih pada perwujudan hak asasi manusia untuk bebas dari rasa takut, terpenuhi hak-hak asasinya untuk bebas dari kekerasan dan memperkuat perdamaian.

Da lam konteks paradigma pembangunan, konsep human security menjadi landasan untuk menjamin kemanusiaan. Hukum diharapkan menjadi penjamin bagi nilai kemanusiaan itu sendiri. Termasuk dari pelbagai tindakan radikalisme yang mengatasnakanan agama untuk melakukan kekerasan terhadap sesamanya, maka hukum menjadi pengawal harkat dan martabat manusia agar masyarakat bebas dari rasa takut untuk beragama dan beribadah.

Dibutuhkan beberapa kondisi untuk dapat mengakselerasi perlindungan hukum dalam wadah pluralitas bangsa Indonesia yakni :

a. Adanya Civil society yang independen, sehat dan cerdas politk.

b. Supremasi hukum yang menjunjung persamaan di muka hukum yang menjadi garansi kostitusional (Constitutional guarantee ) terhadap pemenuhan dan proteksi HAM khususnya Hak atas kebebasan beragama dan beribadah di Indonesia..

c. Birokrasi negara yang melayani kepentingan otoritas demokrasi dan bukan diskriminatif SARA.

d. Penguatan identitas Kebangsaaan Indonesia yang toleran dan progresif sebagai pembangunan kesadaran diri kolektif menduduki peran penting untuk mengeliminasi intoleransi agama dan kekerasan berbaju agama, serta menghadirkan negara dalam mewujudkan Pancasila. Dalam kerangka pendidikan kebangsaan yang berkedamaian, maka pendidikan agama juga diarahkan kearah inklusivisme dan menjadi daya konstruktif dan bukan daya destruktif guna mewujudkan habitus kerukunan antar umat beragama . Beberapa kondisi tersebut di atas, akan melingkupi secara keseluruhan membangun sistem hukum yang meliputi elemen substansi ( substance of $l a w$ ), e l e m e n kelembagaan/institusi (structure of law), maupun pada tataran kultur (ide yang mengatasi perilaku (culture of law) yang lebih mengakomodasi isu strategis dan tanggap terhadap kehidupan harmonisasi sosial bangsa khususnya dalam kehidupan antara umat beragama dalam bermasyarakat dan bernegara di Indonesia .

\section{Simpulan}

Indonesia sebagai negara hukum memiliki sumber segala sumber hukum yakni Pancasila yang melahirkan produk hukum maupun implementasinya yang responsive terhadap Hak Asasi Manusia terutama dalam hal ini hak untuk kebebasan beragama dan menjalankan ibadah. Tuntutan kepada substansi hukum untuk memberikan penghormatan, pemenuhan dan perlindungan terhadap hak-hak dasar dan kebebasan manusia warga negara di satu sisi, dan pada sisi yang lain pembatasan kekuasaaan negara untuk tidak mengeliminasi hak beragama dan kebebasan menjalankan ibadahnya, serta membebaskan warga negara dari diskriminasi berdasar agama. Akuntabilitas negara juga penting untuk mengeliminasi radialisasi 
agama.Sudah menjadi kewajiban negara untuk to respect, to fulfill dan to protect Hak asasi manusia untuk bebas dari kekerasan atas nama apapun, termasuk kekerasan atas nama agama.

Perkembangan positif bagi kontribusi hukum adalah kesetiaan praktik hukum dan insitusi hukum dengan mengabaikan latar belakang ideology dan identitas untuk mengantarkan proses kesejahteraan sosial rakyat yang damai dan bekeadilan. Institusionalisasi Pancasila dalam wajah pluralisme agama dari bangsa Indonesia melalui hukum adalah sebuah keniscayaan .

\section{Daftar Pustaka}

Beckford James A, 2003, Sosial Theory and Religion, New York, Cambridge University Press.

Deputi Bidang Pencegahan, Perlindungan dan Deradikalisasi, 2015, Anak Muda Cerdas Mencegah Terorisme, Badan Nasional Penanggulangan terorisme.

Diamond Larry, 2000, The End of The Third Wave and The start of The Fourth dalam Plattner, Marc F, Joao Carlos Espada, The Democratic Invention, Baltimore, The John Hopkins University Press.

Fitriciada Aidul, "Negara Hukum Indonesia: Dekolonisasi dan Rekonstruksi Tradisi", Jurnal Hukum Ius Quia Iustum, Vol. 19, No.4, Oktober 2012, ISSN 0854-8498

Gunaryo Achmad, 2013, dalam seminar Internasional Membangun Budaaya Perdamaian Melalui Pendidikan Perdamaian di Indonesia, SPWC kerja sama dengan UBCHEA dan Bina Dhrma, 29-30 Mei 2013, Prociding ISSN : 978-979-8154-82-9.

Haryatmoko, 2011, Etika Publik :Untuk Integritas Pejabat Publik dan Politisi, Jakarta, Gramedia Pustaka Utama.

Knitter Paul F, 2005, "is the Pluralist model a Western Imposition ?: A Response in five voices. "In The Myth of Religious Superiority : A Multifaith Exploration, edited by Paul F.Knitter, New York, Orbics Books.

Manan Munafrizal, 2015, "Konstitusi Masyarakat Terbelah", Harian
Kompas, 20Agustus 2015.

Parasong Ali Taher, "Internalisasi Nilai-Nilai Pancasila Dalam Pembentukan Perundang-undangan", tersedia di website https://fh.umj.ac.id, diakses pada tanggal 29 Februari 2016.

Prasetyo Teguh, 2016, Sistem Hukum Pancasila (Sistem, Sistem Hukum dan Pembentukan Peraturan Perundangundangan di Indonesia, Perspektif Teori Keadilan Bermartabat, Bandung, Nusa Media. 